\title{
PERCEPTION AND KNOWLEDGE ON EXCLUSIVE BREASTFEEDING AMONG WOMEN ATTENDING ANTENATAL AND POSTNATAL CLINICS. A STUDY FROM MBARARA HOSPITAL - UGANDA, AUGUST 2008.
}

By: Ampeire Isaac Petit (MD4, MUHAS-2007/2008)

\section{ABSTRACT \\ OBJECTIVE}

Assessment of the perception and knowledge on EBF practice among women attending antenatal and infant follow up clinics in Mbarara hospital, Uganda in August 2008.

\section{METHODOLOGY}

This was a Descriptive Cross-sectional study.

\section{RESULTS}

From a total of 203 respondents, $49.8 \%$ had exclusively breastfed their infants for six months, $12.3 \%$ for more than six months.

The majority of the respondents, $73.8 \%$, knew that a child is supposed to be exclusively breastfed for six months. The main advantage of EBF perceived by $55.2 \%$ of the women who were interviewed was nutrition. The main disadvantage of exclusive breastfeeding perceived by the women was depletion of the mother's health, in only $20 \%$. However majority, $66 \%$ perceived that EBF had no disadvantage. Milk not being enough was the main reason why women did not exclusively breastfeed. The preferred duration of breastfeeding was 18 months in $58 \%$ of the women and the main source of information was the health facilities for $48 \%$ of the women.

\section{CONCLUSION}

The results from this study showed that women have increased knowledge about exclusive breastfeeding. But the perception that EBF is not disadvantageous to the child was substantial. The health facilities provided a good source of information for mothers in Mbarara. Therefore it can be concluded that strengthening this mode of providing information can help to raise the prevalence of EBF significantly.

\section{INTRODUCTION}

Breastfeeding is the process of feeding the infant with mother's milk, either by direct nipple-baby mouth contact or by expressed breast milk. Breast milk is of two types: Colostrum which is the initial yellowish and sticky milk produced from mother's breasts from 37 weeks of gestation to about seven days after delivery; and Mature milk which is whitish in color and is effectively produced from about $10^{\text {th }}$ day following delivery. ${ }^{1}$
Exclusive breast feeding is the practice of feeding the infant for the first six months of life on breast milk only, without any other type of food, not even water. $E B F$ is recommended as the best feeding alternative for infants up to six months and has a protective effect against mortality and morbidity.

Colostrum is important for the baby as it contains more protein [ $10 \%$ compared to $1 \%$ in mature milk], immunoglobulins [IgA], lactoferrin, white blood cells, vitamin A, zinc and less fat. These are important 
for immune defenses of the baby during the initial days of life. ${ }^{1}$

EBF is associated with multiple advantages to both, the baby and the mother. On the baby's side, there is acquisition of passive immunity against infection, nutrients for physical and mental development, emotional security and closeness to the mother. Being a dynamic and physiologically sensitive process, breast milk production is adjusted to suit the infant's requirement according to environmental changes. For example, breast milk will contain more fat during cold seasons. $^{2}$

The current World Health Organization [WHO] recommendations on breastfeeding stipulate that breastfeeding should start immediately following delivery for the baby to get colostrum. The infant should thereafter be exclusively breastfed for up to six months of life, day and night on child's demand. During this period, no fluids including water should be given to the baby. However, there is a room for giving oral medication to the infant should he/she fall sick.. Breastfeeding should still continue until the child is two years of age. The use of bottle-feeding, teats and pacifiers is discouraged as it is associated with poor hygiene and the risk of gastrointestinal infection to the infant. ${ }^{3}$

Globally, there is a declining trend of breastfeeding. Reasons for declining breastfeeding include lack of confidence that the child is getting enough, increased urban women work load demand that makes them to be separated from their babies for longer hours, decline in social support, discomfort on breastfeeding in public, and intense promotion of commercial milk formulae. ${ }^{4}$

Globally, there are new initiatives to encourage EBF. These include the International Code of Marketing Breast milk Substitutes and Baby Friendly Hospital Initiative [BFHI]. Mothers can obtain information about EBF when they are attending antenatal clinic and following hospital delivery. Mass media like radio and television are also helpful in disseminating public education on breastfeeding. ${ }^{4}$

The mother will also benefit from EBF by experiencing lactational amenorrhea, fast return of the uterus to its normal size, prevention of postpartum hemorrhage, reduced risk of getting cancer of the breast and ovary, low risk of osteoporosis and emotional satisfaction. Also breast milk is cheap compared to other artificial feeding.

\section{METHODOLOGY}

\section{Study Design}

It was a Descriptive Cross-sectional study

\section{Study Area}

The infant follow up and antenatal clinics in Mbarara regional hospital, Uganda

\section{Target Population}

All mothers and multigravidae pregnant women, who attended infant follow up and antenatal clinics in Mbarara regional hospital, Uganda in august 2008.

\section{Sampling Method}

Randomized sampling technique was used. The target sample size was 254 breast feeding mothers, however only 203 were interviewed.

\section{Data Collection and Management.}

The information was collected from the study candidates by the use of a self administered structured questionnaire.

\section{RESULTS}

\section{TABLE 1 The proportion of women who exclusively} breastfed their children for the first six months

\begin{tabular}{|l|l|l|}
\hline $\begin{array}{l}\text { Age of starting } \\
\text { other feeds }\end{array}$ & Frequency & Percentage \% \\
\hline$<1$ month & 11 & 5.4 \\
\hline $2-4$ months & 66 & 32.5 \\
\hline 6 months & 101 & 49.8 \\
\hline$>6$ months & 25 & 12.3 \\
\hline Total & 203 & 100.0 \\
\hline
\end{tabular}

From a total of 203 respondents, $49.8 \%$ (101) had exclusively breastfed their infants for six months.

\section{TABLE 2 Knowledge of mothers on duration of exclusive breastfeeding}

\begin{tabular}{|l|l|l|}
\hline $\begin{array}{l}\text { Known Duration of } \\
\text { exclusive breastfeeding }\end{array}$ & Frequency & $\begin{array}{l}\text { Percentage } \\
\%\end{array}$ \\
\hline$<4$ Months & 30 & 14.7 \\
\hline 6 Months & 150 & 73.8 \\
\hline Others & 23 & 11.3 \\
\hline Total & 203 & $100.0 \%$ \\
\hline
\end{tabular}


Others included; 19 respondents (I do not know), 3 respondents( $>6$ months) and 1 respondent ( 5 months).

Majority of the respondents $150(73.8 \%)$ were knowledgeable about EBF.

Table 3 Commonly perceived disadvantages of EBF among women in Mbarara.

\begin{tabular}{|l|l|l|}
\hline Disadvantage & Frequency & Percentage\% \\
\hline Not enough & 26 & 12.8 \\
\hline Causes infections & 2 & 0.1 \\
\hline Depletes mothers & 41 & 21.1 \\
\hline None & 134 & 66.0 \\
\hline
\end{tabular}

The major disadvantage of exclusive EBF perceived by women in Mbarara was that it depletes the mothers health (41 respondents - $21.1 \%$ ), majority (134 respondents - 66.0\%) of the mothers perceived exclusive breastfeeding has no disadvantage.

Table 4 Reasons why women in Mbarara did not exclusively breastfeed their infants

\begin{tabular}{|l|l|l|}
\hline Reasons & Frequency & $\begin{array}{l}\text { Percentage } \\
\%\end{array}$ \\
\hline Mother busy on job & 15 & 19.7 \\
\hline Milk not enough & 45 & 58.4 \\
\hline Baby failed to BF & 19 & 24.6 \\
\hline Others & 0 & - \\
\hline
\end{tabular}

Among the mothers who did not exclusively breastfeed their infants, the main reason for not exclusive breast feeding was, milk being not enough (45 mothers $58.4 \%)$.

\section{DISCUSSION}

This study has revealed that perception of EBF is good among the women attending antenatal clinic in Mbarara regional hospital. 55\% perceived EBF to be nutritional to their babies and $66 \%$ percieved that EBF had no disadvantage. The study has also shown that these women are knowledgeable about EBF. 73.3\% knew that exclusive breastfeeding is for the first six months of life of the baby, the study further showed that about half of the women $(49.8 \%)$ practice EBF for six months and $12 \%$ for more than six months. Knowledge is an important factor that influences perception and practice in breastfeeding as this study has shown, however in a study done in United Kingdom in 2000 only $8 \%$ had practiced exclusive breastfeeding which was out of expectation with the level of knowledge there.

Although few of the previous studies detail perceptions towards EBF, for example a study in central Tanzania showed that women preferred to stop EBF during the rainy season, it does not talk about perceived importance of EBF to their babies which perhaps would be the main driving force to foster this practice. This study has shown that most women considered EBF nutritional to their babies, which can be one of the reasons that can explain the high prevalence of EBF in this study. Majority of the women perceived that EBF has no disadvantage to the baby, although the most perceived disadvantage was that breast milk is not enough for the baby, this could be due to the poor nutrition of the mothers or presence of illness in the mothers.

In the same study mentioned above done in Tanzania, the total duration of breastfeeding was up to 24 to 36 months, with no elaborate reason but the child's demand to breastfeed, but in this study, the average total time of breastfeeding that most women preferred was 18 months, possible causes for this difference are that it could have resulted from the health education they received or also because they perceive that the child has grown up and no longer needs to breastfeed as was the case for most women that were interviewed. From this study very few women would breastfeed the baby until it stops on its own, compared to the breastfeeding on demand described in the central Tanzania study.

Another study done in Ibadan, Nigeria showed that the prevalence of EBF was $39.6 \%$, whereas the prevalence of EBF for six months in this study was $49.8 \%$, a little higher than the previous studies. The factors that can explain this are variable, ranging from the sample sizes used in these studies being bigger than in this study and most of these studies were done in rural areas where as this study dwelled much on the urban women whom are are more educated and informed than their rural counterparts and hence more likely to have a better practice of EBF. However, in all the three studies the prevalence of breastfeeding is still lower than it should be.

In this study out of $37.9 \%$ of those women who did not exclusively breastfeed their children, majority 
(50\%) of these said it was because the breast milk was not enough, $24.6 \%$ said it was because the baby failed to breastfeed, and only $19.4 \%$ of these said it was due to the mother being busy at the job.

The use of the sample of the women attending antenatal clinic to determine the prevalence of exclusive breastfeeding in the urban area is a good representation of the general population upon which conclusions can be substantiated and hence guide a course of action.

\section{CONCLUSION}

The results from this study showed that women have increased knowledge about EBF but perceiving that exclusive breastfeeding is not disadvantageous to the child was substantial.Women prefer to breastfeed their children for more months after EBF for six months, the practice of exclusive breastfeeding was impressive..

\section{RECOMMEDATIONS}

The prevalence of EBF was a little higher than the previous studies but it was less than is required. This reflects on the way the women obtained the knowledge about EBF. The health education given at the health facilities should be enhanced in a way to give more detailed information about exclusive breastfeeding, it's short and long term benefits of colostrum.

To educate about breastfeeding practices, this should be done at the primary school level where through health and science education young girls can learn about the importance of colostrums, and the recommended time duration for breastfeeding for the better growth of the child this should be incorporated in the primary school curriculum.

Public seminars should be conducted to teach the old women who have not been to school, about breastfeeding practices. In addition to the health education this will enable them to advise their younger daughters about the right practices of breastfeeding.

Governments should put a provision to allow mothers to practice exclusive breastfeeding, even when working. It was realized in some mothers that they were busy at work and could not get enough time to breastfeed continuously.

The media can also be used to offer the exact message to the mothers and the rest of the community. Educating both the father and mother of the child will improve the chances of practicing exclusive breastfeeding.

A more analytical study is required to reach a proper conclusion that the prevalence of exclusive breastfeeding has increased compared to previous study results.

\section{ACKNOWLEGDEMENT}

I wish to express my sincere gratitude to first, my supervisor Dr. Furaha Augustine who guided me through the research proposal development and approval.

I particularly thank my dear brother Mr. Matsiko Nicholas for the assistance he offered me in data handling, analysis and use of computer software.

I am further grateful to the administration of Mbarara national referral hospital for allowing me to do my study in their premises. I am particularly grateful to the head of department of obstetrics and gynaecology Prof. Sanchez and his colleagues who enabled me to collect my data. I am also very thankful to the cooperative respondents in the hospital as it is through their cooperation that I have been able to write this report.

Above all I thank my family and friends for the spiritual help and the Almighty God for the life and health I have that has seen me through this study and this report.

\section{REFERENCES}

1. Brown KH, Dewey KG, Allen LH, Complementary Feeding of Young Children in Developing Countries: A review of current scientific knowledge, WHO/UNICEF 1998.

2. Dickin K, Griffiths M, Piwoz E, Designing by Dialogue A program planner's guide to consultative research to improve young child feeding. Washington DC: Academy for Educational Development 1997.

3. Stuart C, Christoph L: Obstetrics by Ten Teachers, $17^{\text {th }}$ edition; 2000.

4. Amin M, Matthews L, Johnson T, Kilty L, Riley R:The prevalence of breast-feeding in south Leicestershire; Br. J Community News;2000. 